\title{
Instrumentos legais como ferramentas para redução de riscos e desastres a inundações
}

\author{
Rafaela Vieira \\ Universidade Regional de Blumenau - Blumenau - SC - Brasil \\ ORCID: https://orcid.org/0000-0001-6668-8758 \\ Leandro José Isensee \\ Universidade Regional de Blumenau - Blumenau - SC - Brasil \\ ORCID: https://orcid.org/0000-0002-5021-474X \\ Gilson de Oliveira Claudino \\ Universidade Regional de Blumenau - Blumenau - SC - Brasil \\ ORCID: https://orcid.org/0000-0003-2429-9425
}

\begin{abstract}
Resumo
Inundações urbanas são frequentes, porém com adensamento urbano e a impermeabilização da terra (consequência e probabilidade), tendem a elevar o risco de desastres. Buscando reduzir este risco, o objetivo desta pesquisa é analisar como os instrumentos legais estão potencializando ou mitigando o risco de inundações nas principais cidades da Bacia Hidrográfica do Itajaí. Para alcançar este objetivo, realizou-se uma pesquisa descritiva nos Planos Diretores e em legislações municipais de Rio do Sul, Blumenau e Itajaí, com foco intra-lote, analisando os índices urbanísticos, em especial taxa de ocupação e taxa de permeabilidade. Estes índices foram relacionados com o mapa de zoneamento e quantificados em termos de município, sendo então possível uma análise comparativa. Utilizou-se também o zoneamento dos municípios para uma sobreposição aos mapas de áreas inundáveis. Os resultados demonstram que o município de Itajaí possui as maiores taxas de ocupação permitidas e as menores taxas de permeabilidade exigidas. Em relação as áreas inundáveis, os municípios de Rio do Sul e Itajaí possuem zonas com incentivo a ocupação dentro de áreas suscetíveis a inundações. Além disso, como outras medidas intra-lote para retardar o escoamento superficial de águas pluviais, apenas Blumenau possui legislação específica ao incentivar o uso de "Telhado verde". Portanto, conclui-se que as legislações municipais dos municípios analisados não têm incentivado a sustentabilidade urbana e que seus índices urbanísticos estão contribuindo para a ampliação do risco de desastre a inundações.
\end{abstract}

Palavras-chave: Inundação. Planejamento urbano e ambiental. Taxa de ocupação. Taxa de permeabilidade. Zoneamento. 


\section{Legal instruments as tools for flood risk and disasters reduction}

\section{Abstract}

Urban flood is a frequent phenomenon nowadays, however urban densification and land sealing (consequence and probability), tend to enhance the risk of disasters. Aiming to reduce such risk, the objective of this work is to analyze how the legal instruments are potentiating or mitigating the risk of flooding in the main cities of the Itajaí river basin. To achieve this objective, we carried away a descriptive research over municipal master plans and legislations of Rio do Sul, Blumenau and Itajaí, with an intra-plot focus, analyzing the urbanistic indices: occupancy rate and permeability rate. These indices were related to the urban zoning map and quantified by city, making possible a comparative analysis. The urban zoning maps were also used to overlap the flooded area maps. Results show that Itajaí has the highest occupancy rates allowed and the lowest permeability rates required. Regarding the potential flood affected areas Rio do Sul and Itajaí have zones with occupation incentive within areas susceptible to flooding. In addition, like other intra-plot measures to slow down runoff of rainwater, only Blumenau has specific legislation encouraging the use of "green roof". Therefore, it is concluded that the municipal laws of the analyzed cities have not encouraged urban sustainability, and their urban indexes are contributing to the increase the flood disaster risk.

Keywords: Flooding. Urban and environmental planning. Occupancy rate. Permeability rate. Urban zoning.

\section{Instrumentos legales como herramientas para la reducción del riesgo de desastres Resumen}

Las inundaciones urbanas son frecuentes, pero la densificación urbana y la impermeabilización del suelo (consecuencia y probabilidad), tienden a aumentar el riesgo de desastres. Con la intención de reducir este riesgo, el objetivo de esta investigación es analizar cómo los instrumentos legales están agravando o mitigando el riesgo de inundaciones en las principales ciudades de la cuenca del río Itajaí. Para lograr este objetivo, se realizó una investigación descriptiva de los planes de uso y ocupación de la tierra y de las leyes municipales de Rio do Sul, Blumenau e Itajaí, centrándose en las medidas dentro del lote, especialmente los coeficientes de ocupación y permeabilidad del suelo. Estos índices se relacionaron con el mapa de zonificación y el área del municipio, haciendo posible un análisis comparativo. Se utilizó la zonificación de los municipios también para superponer los mapas de áreas inundadas. Los resultados muestran que el municipio de Itajaí tiene los coeficientes de ocupación más altos permitidos y los coeficientes de permeabilidad del suelo más bajos requeridos. Con respecto a las áreas inundadas, los municipios de Rio do Sul e Itajaí tienen zonas con incentivos de ocupación dentro de las áreas susceptibles a las inundaciones. Además, al igual que otras medidas dentro del lote para reducir la escorrentía de las aguas pluviales, solo Blumenau tiene una legislación específica que fomenta el uso del "techo verde". Por lo tanto, se concluye que las leyes municipales de estos municipios no han fomentado la sostenibilidad urbana y sus índices urbanísticos están contribuyendo al aumento del riesgo de desastres por inundaciones.

Palabras clave: Inundación. Planificación urbana y ambiental. Coeficiente de ocupación. Coeficiente de permeabilidad. Zonificación.

\section{Introdução}


Inundações são desastres naturais que ocorrem quando as águas extravasam seu leito de escoamento, seja este leito natural (rios) ou artificial (galerias pluviais) (TUCCl, 2003). Nos últimos anos estes desastres têm aumentado em intensidade e frequência, sendo que no Brasil foram registradas 4.691 inundações severas entres os anos de 1991 e 2012 (CEPED, 2013; SIEBERT, 2017).

No contexto estadual de Santa Catarina, houve o registro entre os anos 1991 e 2013, que as enxurradas (inundações rápidas) deixaram mais de 79 mil desabrigados, 295 mil desalojados e ocasionaram 168 falecimentos. Já as inundações causaram 33.203 desabrigados, 175.130 desalojados, 4 desaparecidos e 38 mortes. Neste contexto, a mesorregião do Vale do Itajaí foi a mais afetada no Estado, com 27\% do total de enxurradas e 23\% do total de inundações (CEPED, 2013).

Embora as inundações sejam um processo de causa natural (chuva), os riscos de inundações podem ser parcialmente geridos através de políticas de uso e ocupação do solo. É consenso no meio técnico que se deve buscar soluções integradas e sustentáveis para a drenagem urbana, evitando a abordagem higienista que visa esconder e afastar as águas pluviais dos centros urbanos, o que costuma aumentar os impactos a jusante das cidades (CRUZ; TUCCI, 2008; ANELLI, 2015; CANHOLI, 2015).

Com base nisso, esta pesquisa visa analisar como os instrumentos legais, especialmente a taxa de ocupação e de permeabilidade, estão potencializando ou mitigando o risco de inundações nas principais cidades da Bacia Hidrográfica do Itajaí.

\section{Gestão de risco de desastres}

Os modelos de desenvolvimento agressivos juntamente com a carência de políticas públicas de ordenamento territorial acarretaram inúmeros desastres notáveis no século XX (BARRIOS; CABRERA; VEGA-ESTARITA, 2018). Conforme proposto por Cuny (1983), aqueles desastres eram problemas não resolvidos do desenvolvimento. Assim, os desastres se tornaram um forte fator limitante para 0 desenvolvimento, o que motivou, como resposta, o surgimento do conceito de gestão de risco de desastres (PINTO, 2012).

O que tem sido notado é que a curto prazo, o aumento das crises humanitárias e outras preocupações em relação à riscos de desastres, exigiram ações rápidas e eficientes de preparação e respostas às emergências. A longo prazo, essas exigências moveram o aprimoramento de métodos, desenvolvimento de tecnologias e procedimentos de gestão de riscos de desastres que visam ações de enfrentamento e prevenção contra emergências (OLIVER-SMITH et al., 2017).

Essas ações de enfrentamento ganharam força através de iniciativas institucionais internacionais que promoveram uma série de eventos marcantes para a gestão de risco de desastres. Inicialmente, a década de 1990 foi marcada como a Década Internacional para a Redução de Desastres Naturais, seguida pela Estratégia de Yokohama e o Plano de Ação para o Mundo Mais Seguro (1994) e o Marco de Ação de Hyogo (2005-2015) (OLIVER-SMITH et al., 2017).

No atual cenário, a Terceira Conferência Mundial sobre a Redução do Risco de Desastres foi marcada pelo acordo voluntário instituindo o Marco de Sendai (2015-2030) (UNISDR, 2015) pelos estados-membros da Organização das Nações 
Unidas (ONU). Este marco estabeleceu o plano global de redução do risco de desastres, que tem por finalidade a prevenção de novos riscos de desastres, reduzir os já existentes e adotar medidas que fortaleçam as ações de resiliência (MENA, 2018).

Ressalta-se que o Marco de Sendai define quatro prioridades de ações na gestão de riscos de desastres (GRD) que envolvem (1) geração de conhecimento sobre riscos de desastres; (2) fortalecimento da governança para o gerenciamento dos riscos de desastres; (3) aumento de investimentos na prevenção e redução de riscos de desastres para melhorar a resiliência das pessoas; e (4) aprimoramento da preparação contra desastres para ter uma resposta rápida e melhorar a recuperação, reabilitação e reconstrução (UNISDR, 2015).

Apesar do Marco de Sendai ser o norteador para a gestão de risco de desastres nos estados-membros, é reconhecidamente notável a diferença de realidades e abordagens quanto ao assunto. Em países desenvolvidos, as ações vão além das ferramentas tradicionais de gestão (políticas, obras, medidas) e abordam, por exemplo, a mitigação, cobertura de seguros e gestão de crise; enquanto em países em desenvolvimento, a gestão de riscos não se apresenta como prioritária, tendo em vista outros problemas mais emergenciais que fazem parte da realidade desses países (ALMEIDA, PASCOLINO, 2009).

Mesmo assim, alguns países em desenvolvimento conseguiram construir uma base sólida para lidar com a gestão de riscos de desastres. No Brasil, a Lei $\mathrm{N}^{\circ}$ 12.608, de 10 de abril de 2012, instituiu a Política Nacional de Proteção e Defesa Civil (PNPDEC) (BRASIL, 2012) fortalecendo o processo de gestão de riscos de desastres ao incorporar a sociedade civil e ao estabelecer a necessidade da abordagem sistêmica para as ações de prevenção, mitigação, preparação, resposta e recuperação (BRASIL, 2012).

Em vista os principais tipos de desastres no Brasil serem os eventos geohidrológicos, como movimentos de massa e inundações (CEPED, 2013), tem sido necessário uma articulação entre os mais diversos instrumentos de gestão de risco de desastres, por isso a importância da PNPDEC para o país, pois seu objetivo é "integrar-se às políticas de ordenamento do solo, desenvolvimento urbano, saúde, meio ambiente, mudanças climáticas" (BRASIL, 2012) entre outras. Além disso, no aspecto legal e administrativo, o estabelecimento das atribuições governamentais nas esferas federal, estadual e municipal, têm colaborado para o enfrentamento e minimização de riscos e impactos de desastres (COUTINHO, 2015).

\section{Do risco de desastres às inundações}

Para Narváez, Lavell e Ortega (2009), a definição de "risco de desastre" seguiu dois rumos ao longo do tempo, aquele que se baseia nas ciências da terra, tendo foco na probabilidade da ocorrência de um evento físico danoso, e naquele associado ao meio socioeconômico, que inclui a probabilidade das perdas e danos devido a ocorrência de um evento.

Em um ponto de vista colocando o ser humano no centro da análise, Almeida e Pascoliano (2009) afirmam que o risco está associado à percepção humana quanto à possibilidade de ocorrência de um evento danoso ou que possa causar prejuízo. Assim, para os autores, o conceito de risco só existe se houver pessoas 
que o percebam e/ou sofram por um episódio lesivo, em que as consequências dependem da vulnerabilidade pertencente ao indivíduo ou grupo.

A vulnerabilidade, juntamente com os eventos físicos, compõe os fatores de risco de desastre. A vulnerabilidade decorre de processos sociais e mudanças ambientais que envolvem a combinação entre a precariedade das condições de vida, que tornam alguns grupos de pessoas vulneráveis aos desastres, e as alterações ambientais que fazem determinadas áreas se tornarem vulneráveis à ocorrência de ameaças e eventos danosos. Os eventos físicos são aqueles fenômenos que possuem grande poder destrutivo ou causam efeitos prejudiciais à sociedade, como os desastres naturais (NARVÁEZ; LAVELL; ORTEGA, 2009; FREITAS et al, 2014).

De maneira geral, os desastres são eventos que causam perturbação significativa sobre o funcionamento de uma comunidade, gerando-as perdas humanas, materiais, econômicas ou ambientais que excedem a capacidade suporte da comunidade arcar isoladamente com seus próprios recursos (UN, 2007 apud MINERVINO; DUARTE, 2016). Os desastres naturais, segundo a Codificação Brasileira de Desastres (COBRADE), podem ser classificados em geológico (referente a terremotos, emanação vulcânica, movimentos de massa e erosão), biológico (epidemias e pragas), climatológicos (secas), hidrológicos (inundações, enxurradas e alagamentos) e meteorológicos (sistemas de grande escala, tempestades e temperaturas extremas).

Com acentuado aumento nas últimas décadas, os desastres naturais têm causado uma série de riscos e prejuízos às vidas humanas e economias mundiais (SILVA et al. 2013). Na América Latina, o aumento de eventos extremos como terremotos, ciclones, desmoronamentos de terra e inundações tem sido frequente nas metrópoles, sendo ainda agravados pelas precárias condições de infraestrutura dessas cidades e por suas grandes concentrações populacionais (ALMEIDA; PASCOALINO, 2009; VALDIVIESO, 2018).

No Brasil, por exemplo, suas características geomorfológicas e socioambientais expõem o país a riscos e desastres naturais relacionados aos fenômenos geofísicos, hidrológicos e climáticos. Devido à falta de planejamento e organização, o processo de urbanização nas grandes cidades brasileiras ocorreu de forma intensa e desigual, o que obrigou a população menos favorecida a ocupar áreas impróprias para habitação, tornando-as vulneráveis aos desastres hidrológicos, como deslizamentos de massas úmidas e inundações (ALMEIDA; CARVALHO, 2010; BAO; GIUDICE, 2014)

Assim como os desastres hidrológicos representam quase metade do total de desastres ocorridos no mundo (GUHA-SAPIR et al., 2015), no Brasil, especificamente as inundações, são as principais causas de danos humanos e materiais em áreas urbanas (ALMEIDA; CARVALHO, 2010). Por exemplo, em 2008, os desastres provocados pelas inundações obrigaram cerca de 650 famílias das zonas sul e leste da cidade de São Paulo/SP e do ABC paulista a deixarem suas casas. Apenas na cidade de São Caetano do Sul/SP, 500 famílias foram desalojadas, e na cidade próxima, Mauá/SP, 60 famílias ficaram desalojadas e 3 desabrigadas (POLETO, 2011)

Contudo, é no estado de Santa Catarina que tem sido frequente as ocorrências de desastres causados por inundações. Até o ano 2000, Pompêo (2000) 
constatou que as inundações atingiam anualmente a população de $70 \%$ dos municípios do estado e em $66 \%$ deles, as inundações localizadas repetiam mais de uma vez ao ano. Em análise com dados entre 1991 a 2012, o estado registrou oficialmente 449 casos de inundações excepcionais caracterizadas como desastre, na qual 104 registros ocorreram apenas na mesorregião do Vale do Itajaí, representando $23 \%$ de todo o estado (CEPED, 2013).

O elevado número de ocorrências de inundações no Vale do Itajaí pode ser explicado por suas características físicas e geológicas, como a topografia acidentada, geologia frágil, precipitações intensas e duradouras e ocupação desordenada, tornando-a suscetível a desastres naturais (SIEBERT, 2009).

No ano de 2008, quando o Vale do Itajaí registrou índices anormais de chuvas fortes, as inundações e outras ocorrências que compõem os desastres naturais, foram responsáveis por 14 municípios decretarem estado de calamidade pública e 63 situações de emergência (AVILA; MATTEDI, 2017).

\section{Uso e ocupação do solo}

A Constituição da República Federativa do Brasil (BRASIL, 1988), prevê que cabe aos Municípios executar um adequado ordenamento do seu território, através do planejamento e controle do uso do solo urbano, de modo a garantir o bem-estar de seus cidadãos. Para isso, o instrumento básico que os Municípios possuem para promover a política de desenvolvimento e de expansão urbana é o Plano Diretor (BRASIL, 2001).

Com o objetivo regulamentar os artigos que tratam da política urbana presentes na Constituição Federal, e de "[...] estabelecer normas de ordem pública e interesse social que regulam o uso da propriedade urbana em prol do bem coletivo, da segurança e do bem-estar dos cidadãos, bem como do equilíbrio ambiental" (BRASIL, 2001) foi sancionada a lei no 10.257, de 10 de junho de 2001, denominada Estatuto da Cidade. Esta lei tem um papel importante no planejamento urbano e ambiental do Brasil, pois estabelece que a ordenação e o controle do uso do solo devem, dentre outros itens, evitar a degradação ambiental. No entanto, embora a Constituição Federal (BRASIL, 1988), diga que deve haver uma competência comum entre os entes federativos, com o objetivo de promover melhorias nas condições habitacionais, bem como o equilíbrio e bem-estar dos cidadãos, cabe ao município legislar sobre o uso e ocupação de seu território (BRASIL, 1999).

Para isso, o processo de planejamento urbano municipal tem como instrumento o Plano Diretor, cuja principal função é promover a função social da propriedade em detrimento de interesses privados. Para isso, o Plano Diretor dispõe dos índices e instrumentos urbanísticos, que servem de base para a definição do uso e ocupação do solo. Estes índices, podem ou não estar presentes no próprio Plano Diretor, quando o estão, o Plano Diretor é classificado como autoaplicável (PINTO, 2011, DENALDI et al. 2017).

Seguindo as diretrizes do Estatuto das Cidades (BRASIL, 2001), em que o equilíbrio ambiental foi inserido como um objetivo, outros parâmetros urbanísticos foram sendo instituídos. Um exemplo disto é a chamada taxa ocupação e permeabilidade do solo. O primeiro parâmetro diz respeito ao percentual máximo 
de superfície que um lote pode ser ocupado, já o segundo especifica a área permeável mínima que o lote deve preservar, para garantir a infiltração da água no solo (KAUFFMANN; SILVA, 2005). Estas medidas expostas são consideradas medida intra-lote, não estruturais, que visam combater e reduzir os impactos negativos gerados pela urbanização acelerada, bem como reduzir a vulnerabilidade e a exposição as inundações (BEZERRA, 2015; DECINA; BRANDÃO, 2016).

\section{Procedimento metodológico}

5.1 Área de estudo

Os municípios alvo desta pesquisa foram:

- Rio do Sul - 61.198 habitantes, área territorial 260,817 km², $22 \%$ da população da microrregião do Alto Vale (IBGE, 2010);

- Blumenau - 309.011 habitantes, área territorial 518,619 km², 44 \% da população da microrregião do Médio Vale (IBGE, 2010);

- Itajaí - 215.895 habitantes, área territorial $288,402 \mathrm{~km}^{2}, 54 \%$ da população da microrregião do Baixo Vale (IBGE, 2010).

Os municípios de estudo estão localizados na Bacia Hidrográfica do Rio Itajaí (BHRI), pertencente ao Estado de Santa Catarina, Brasil (Figura 1). O município mais populoso da bacia é Blumenau, estando localizado nas coordenadas $26^{\circ} 51^{\prime} 10^{\prime \prime}$ de latitude Sul e 49 $03^{\prime} 58^{\prime \prime}$ de longitude Oeste. A bacia abrange 52 municípios, possuindo uma área de aproximadamente $15.000 \mathrm{~km}^{2}$, sendo dividida em três microrregiões: Alto Vale, Médio Vale e Baixo Vale (COMITÊ DO ITAJAÍ, 2010; IBGE, 2010).

A escolha pelos três municípios deu-se por dois motivos. Primeiro, pela importância regional, em vista eles serem polos sócio-econômicos nas suas respectivas microrregiões, no qual os três municípios juntos correspondem a aproximadamente $46 \%$ da população total da bacia (IBGE, 2010). O segundo motivo é pela suscetibilidade a inundações, pois os três municípios são "cortados" pelo principal rio da bacia, o Itajaí-Açu, em suas respectivas microrregiões, tendo o processo urbanização e industrialização feito às margens do rio. Aliado a isso, devido a bacia hidrográfica do Rio Itajaí ter como cabeceira a Serra Geral, as inundações podem ser repentinas e frequentes (ESPINDOLA; NODARI, 2013; AVILA; MATTEDI, 2017). Para fins de comprovação, o histórico de eventos entre os anos 1991 e 2012 mostra que os municípios de Rio do Sul, Blumenau e Itajaí, registraram 41 casos de enxurradas e 17 casos de inundações, tendo média de mais de dois eventos por ano (CEPED, 2013). 
Figura 1. Localização da área de estudo

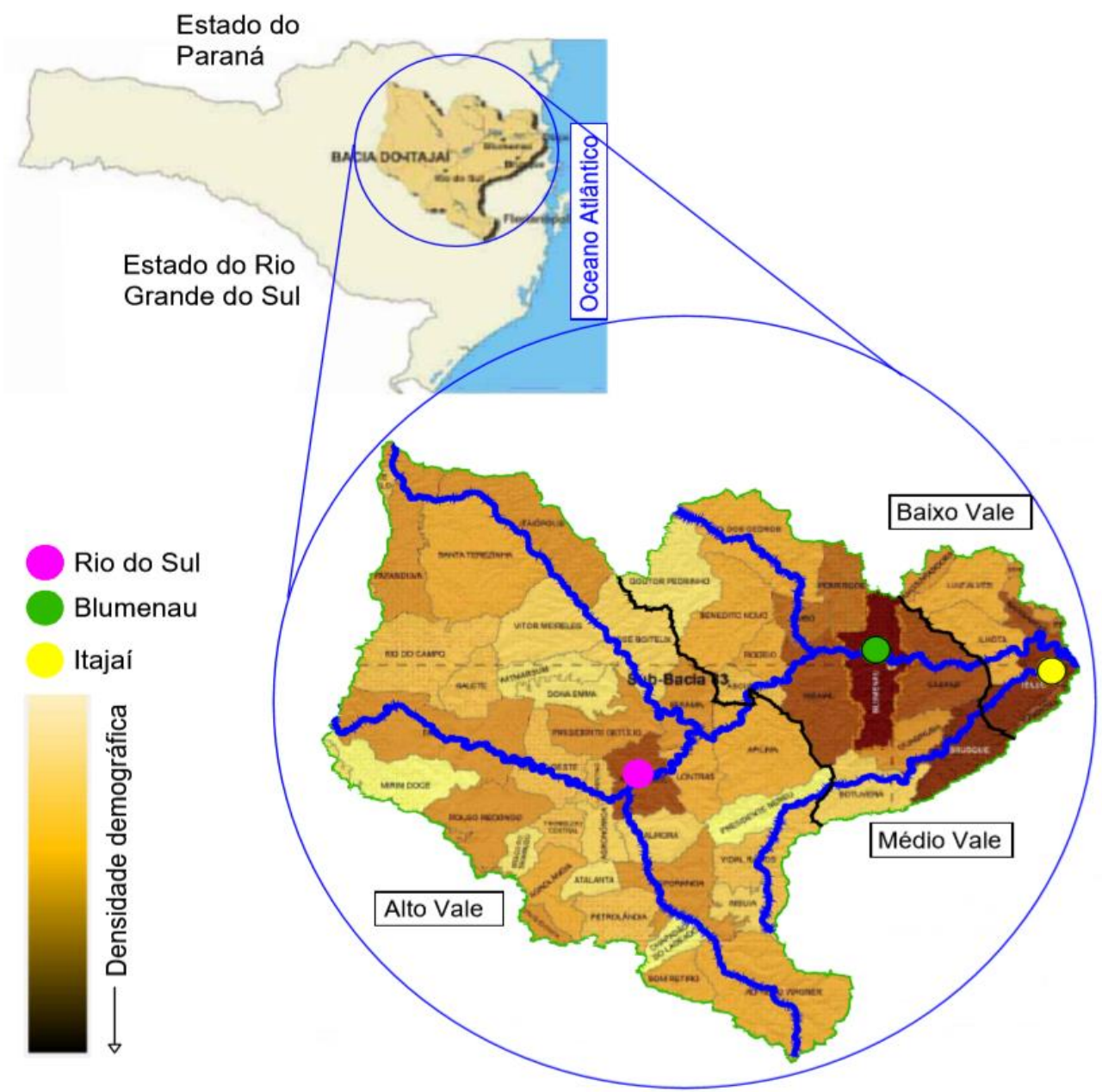

Fonte: Adaptado de Machado e Marcuzzo (2015), Comitê do Itajaí (2010) e IBGE (2010)

5.2 Coleta e tratamento de dados

Para a coleta de dados, buscou-se informações no plano diretor e nas demais legislações de Blumenau, Itajaí e Rio do Sul (Quadro 1), referente aos índices urbanísticos (taxa de permeabilidade e taxa de ocupação) e medidas de incentivo intra-lote para reduzir o risco de inundações. Para isso, foram utilizadas as seguintes palavras-chaves para a pesquisa: água, drenagem urbana, enchente, escoamento, inundação, permeabilidade, pluvial e verde.

Quadro 1. Legislações utilizadas na pesquisa

\begin{tabular}{|c|c|c|c|}
\hline Município & Itajaí & Blumenau & Rio do Sul \\
\hline Plano Diretor Autoaplicável? & Não & Não & Sim \\
\hline & & & LC N $^{\circ} 300 / 2015$ \\
Plano Diretor & LC N N $^{\circ}$ 94/2006 & LC No $1181 / 2012$ \\
& & & LC N $^{\circ} 163 / 2006$ \\
\hline Demais legislações & LC N $^{\circ}$ 215/2012 & LC N $^{\circ} 1174 / 2018$ & \\
\hline
\end{tabular}


Fonte: Elaborado pelos autores.

Análise do zoneamento dos municípios

Após a coleta de dados relativos aos índices urbanísticos, o zoneamento dos municípios foi transformado em unidades de áreas, desconsiderando as zonas de corredores, por representarem áreas pequenas (menos de $0,1 \%$ cada). Portanto, buscou-se os dados junto aos setores de geoprocessamento e cartografia dos três municípios, conforme detalhamento abaixo:

- Em Rio do Sul, foi obtido um mapa do zoneamento do município em formato DWG, e através do software AutoCad $2017^{\circledR}$ (versão estudantil), obteve-se a área de cada zona;

- Em Blumenau, foi obtido diretamente as áreas relativas a cada zona;

- Em Itajaí, não foi possível obter qualquer informação, sendo necessário sobrepor o arquivo do zoneamento, em formato PDF, ao mapa com os limites do município providos da EPAGRI/CIRAM (2019) em formato DXF, obtendo assim as áreas, também através do software AutoCad $2017^{\circledR}$.

Suscetibilidade das zonas a inundações

Para a análise das zonas suscetíveis a inundações, utilizou-se o seguinte procedimento para cada um dos municípios:

- Em Rio do Sul, foi obtido o mapa de inundações disponibilizado pela defesa civil do município. O mapa de inundação escolhido foi o que correspondia ao nível do rio de 10,50, por ser um nível recorrente de inundações, conforme histórico (RIO DO SUL, 2019):

o 2013: nível = 10,39 m;

o 2015: nível = 10,71 m;

o 2017: nível = 10,89 m.

O mapa foi extraído para o formato JPEG, o qual teve sua geometria validada com o mapa de zoneamento, via software AutoCad $2017^{\circledR}$, e então sobreposto ao mesmo. As áreas escolhidas para análise foram as zonas que permitem as maiores taxas de ocupação no município, sendo elas as ZR2 e ZR3;

- Para Itajaí, também foi obtido o mapa de inundações disponibilizado pela defesa civil do município. O mapa de inundação escolhido foi o mais recente disponibilizado para inundações fluviais, sendo o correspondente ao ano de 2011. Este mapa teve sua geometria validada com o mapa de zoneamento, via software AutoCad $2017^{\circledR}$, e então sobreposto ao mesmo. As áreas escolhidas para análise foram as zonas que permitem as maiores taxas de ocupação no município, porém como quase todas possuíam valores elevados, optou-se pelas zonas com a maior representatividade em termos de área, sendo as zonas ZU2, ZU3, ZU4 e ZEU;

- Em relação ao município de Blumenau, não foi possível realizar a avaliação por falta de dados disponíveis. 


\section{Resultados}

\subsection{Composição dos índices urbanísticos}

Na tabela 1, pode-se observar todas as zonas constantes no zoneamento do município de Itajaí. Por meio do tratamento de dados com as taxas máximas de ocupação e mínimas de permeabilidade de cada zona, foi constatado: (1) o percentual de cada zona em relação ao total; (2) o percentual do perímetro urbano; (3) o percentual da área de transição urbano/rural e urbano/proteção ambiental; (4) o percentual da zona de proteção ambiental da zona rural; e (5) a média ponderada das taxas de ocupação e de permeabilidade, em relação a área total do município.

Tabela 1. Zoneamento e índices urbanísticos de Itajaí

\begin{tabular}{ccccc}
\hline ZONA & $\%$ & Uso & $\begin{array}{c}\text { Taxa de } \\
\text { Ocupação }\end{array}$ & $\begin{array}{c}\text { Taxa de } \\
\text { Permeabilidade }\end{array}$ \\
\hline ZU1 & $0,2 \%$ & & $80 \%$ & $10 \%$ \\
ZU2 & $2,9 \%$ & & $80 \%$ & $10 \%$ \\
ZU3 & $3,7 \%$ & & $80 \%$ & $10 \%$ \\
ZU4 & $4,6 \%$ & & $80 \%$ & $10 \%$ \\
ZU5 & $0,4 \%$ & & $80 \%$ & $10 \%$ \\
ZR1 & $0,3 \%$ & & $50 \%$ & $10 \%$ \\
ZR2 & $0,1 \%$ & & $50 \%$ & $10 \%$ \\
ZR3 & $0,3 \%$ & Urbano & $80 \%$ & $10 \%$ \\
ZEU & $2,4 \%$ & $(22,5 \%)$ & $80 \%$ & $10 \%$ \\
ZC2 & $0,7 \%$ & & $80 \%$ & $10 \%$ \\
ZC1 & $0,0 \%$ & & $80 \%$ & $10 \%$ \\
ZIP & $2,3 \%$ & & $60 \%$ & $10 \%$ \\
ZSI & $3,0 \%$ & & $60 \%$ & $10 \%$ \\
ZIT & $0,1 \%$ & & $60 \%$ & $10 \%$ \\
ZPN & $1,3 \%$ & & $60 \%$ & $10 \%$ \\
ZAP & $0,3 \%$ & & $60 \%$ & $10 \%$ \\
\hline ZTRU & $10,0 \%$ & Transição & $60 \%$ & $10 \%$ \\
ZTRA & $1,5 \%$ & $(11,5 \%)$ & $60 \%$ & $10 \%$ \\
\hline ZPA1 & $6,8 \%$ & & $20 \%$ & $20 \%$ \\
ZPA2 & $9,8 \% *$ & Ambiental & $20 \%$ & $20 \%$ \\
ZPA3 & $1,8 \%$ & $(18,6 \%)$ & $20 \%$ & $20 \%$ \\
ZEA & $0,3 \%$ & & $50 \%$ & $20 \%$ \\
ZR & $47,4 \% *$ & Rural & $60 \%$ & $10 \%$ \\
\hline Total & $100 \%$ & & $55,6 \%$ & $11,9 \%$ \\
\hline
\end{tabular}

Fonte: Elaborado pelos autores.

*Valor sujeito a alteração em vista a limitação na representação do mapa de zoneamento.

Com base nos dados da tabela 1 relativos ao município da Itajaí, foi observado que aproximadamente $47,4 \%$ do território municipal é composto de zona 
rural, possuindo taxas de ocupação que variam de 20 a $80 \%$, e a média ponderada da taxa de ocupação em função do território total é de 55,6\%. Ao analisar a taxa de permeabilidade, observa-se uma variação de $10 \%$ a $20 \%$, sendo e a média ponderada igual a $11,9 \%$.

Em relação ao município de Blumenau, foi constatado (Tabela 2) que aproximadamente $61 \%$ do território deste é pertencente a zona rural, e que por possuir taxas de ocupação que variam de 20 a $80 \%$, e a sua média ponderada em função do território total é de 33,7\%. Já analisando a taxa de permeabilidade, observa-se que há um padrão de $20 \%$ para todas as áreas, exceto para a ZLE1 (Zona de Localização Especial 1), na qual permite-se construir com $0 \%$ de permeabilidade no solo; essa zona é composta por imóveis de valor cultural, localizados na área central da cidade (BLUMENAU, 2010).

Tabela 2. Zoneamento e índices urbanísticos de Blumenau

\begin{tabular}{ccccc}
\hline ZONA & $\%$ & Uso & $\begin{array}{c}\text { Taxa de } \\
\text { Ocupação }\end{array}$ & $\begin{array}{c}\text { Taxa de } \\
\text { Permeabilidade }\end{array}$ \\
\hline ZR1 & $7,6 \%$ & & $60 \%$ & $20 \%$ \\
ZR2 & $3,1 \%$ & & $60 \%$ & $20 \%$ \\
ZR3 & $2,2 \%$ & & $70 \%$ & $20 \%$ \\
ZR4 & $2,8 \%$ & & $70 \%$ & $20 \%$ \\
ZLE1 & $0,2 \%$ & & $80 \%$ & $0 \%$ \\
ZLE2 & $0,1 \%$ & Urbano & $70 \%$ & $20 \%$ \\
ZLE3 & $0,0 \%$ & $(22,6 \%)$ & $60 \%$ & $20 \%$ \\
ZC1 & $0,6 \%$ & & $70 \%$ & $20 \%$ \\
ZC2 & $2,1 \%$ & & $70 \%$ & $20 \%$ \\
Zl1 & $3,7 \%$ & & $60 \%$ & $20 \%$ \\
Zl2 & $0,0 \%$ & & $60 \%$ & $20 \%$ \\
ZRU & $0,3 \%$ & & - & - \\
ZPA & $13,2 \%$ & Ambiental & $30 \%$ & $20 \%$ \\
\hline ZAG & $3,4 \%$ & & $30 \%$ & $20 \%$ \\
ZRD & $24,0 \%$ & Rural (64,2\%) & $30 \%$ & $20 \%$ \\
ZRP & $36,8 \%$ & & $20 \%$ & $20 \%$ \\
\hline Total & $100 \%$ & & $33,8 \%$ & $19,9 \%$ \\
\hline
\end{tabular}

Fonte: Elaborado pelos autores.

Por fim, ao analisar o município de Rio do Sul, o tratamento dos dados demonstrou (Tabela 3) que aproximadamente $78 \%$ do território deste município pertence a zona rural. Ainda, assim como os demais municípios, Rio do Sul possui taxas de ocupação que variam de 20 a 80\% e média ponderada da taxa de ocupação, em função do território total, de $26,2 \%$. A taxa de permeabilidade varia entre $5 \%$ e $60 \%$, sendo a média ponderada de $51,8 \%$.

Tabela 3. Zoneamento e índices urbanísticos de Rio do Sul

$\begin{array}{cccc}\text { ZONA } & \text { Uso } & \text { Taxa de } & \text { Taxa de } \\ \text { Ocupação } & \text { Permeabilidade }\end{array}$




\begin{tabular}{ccccc}
\hline ZR1 & $11,0 \%$ & Urbano & $60 \%$ & $20 \%$ \\
ZR2 & $0,9 \%$ & $(20,1 \%)$ & $70 \%$ & $10 \%$ \\
ZR3 & $1,2 \%$ & & & $5 \%$ \\
\hline & & & & $\begin{array}{c}\text { Continua... } \\
\text { Continuação }\end{array}$ \\
\hline ZONA & $\%$ & Uso & Taxa de & Taxa de \\
& & & Ocupação & Permeabilidade \\
\hline ZR1E & $1,1 \%$ & Urbano & $60 \%$ & $20 \%$ \\
ZI & $1,8 \%$ & $(20,1 \%)$ & $20 \%$ & $20 \%$ \\
ZEIS & $0,1 \%$ & Ambiental & $20 \%$ & - \\
\hline ZPA & $3,9 \%$ & $(5,9 \%)$ & - & $50 \%$ \\
APP & $2,0 \%$ & Rural $(78 \%)$ & $20 \%$ & - \\
\hline ZRP & $2,4 \%$ & $100,0 \%$ & $26,2 \%$ & $20 \%$ \\
Zona Rural & $75,6 \%$ & & & $60 \%$ \\
\hline Total & $100,0 \%$ & $10 \%$ & $51,8 \%$ \\
\hline
\end{tabular}

Fonte: Elaborado pelos autores.

Analisando as tabelas 1, 2 e 3, nota-se que, considerando a área total do município, ou seja, incluindo a zona rural, o município de Itajaí possui a maior disparidade, tanto na taxa de ocupação máxima, quanto na taxa de permeabilidade mínima, se comparado com Rio do Sul, sendo que Blumenau está em uma posição intermediária em relação aos outros dois, porém com bastante diferença para Rio do Sul quanto a taxa de permeabilidade mínima. Este resultado pode ser explicado pelo fato da cidade de Rio do Sul ter uma zona rural maior que as demais cidades, e adotar uma taxa de permeabilidade mínima de $60 \%$ nesta zona, ao contrário das demais cidades que adotam $20 \%$.

No entanto, ao observar a tabela 4, que considera a média ponderada da taxa de ocupação e taxa de permeabilidade, apenas na zona urbana (todos os usos exceto rural e de proteção ambiental), foi percebido mudanças no panorama dos resultados. Enquanto o município de Itajaí continua com a maior disparidade na taxa de ocupação máxima e permeabilidade mínima, Rio do Sul e Blumenau apresentam resultados semelhantes, com a taxa de ocupação máxima próxima dos 60\% e a taxa de permeabilidade mínima próxima dos $20 \%$.

Tabela 4. Índices urbanísticos ponderados da zona urbana

\begin{tabular}{cccc}
\hline Municípios & \% Urbano & Taxa de Ocupação & $\begin{array}{c}\text { Taxa de } \\
\text { Permeabilidade }\end{array}$ \\
\hline Itajaí & $22,5 \%$ & $73,0 \%$ & $10,0 \%$ \\
Blumenau & $22,6 \%$ & $63,6 \%$ & $19,9 \%$ \\
Rio do Sul & $20,1 \%$ & $57,6 \%$ & $18,3 \%$ \\
\hline
\end{tabular}

Fonte: Elaborado pelos autores.

A importância do percentual das taxas de ocupação e permeabilidade nos municípios é demonstrada por Decina e Brandão (2016), que ao observarem a ocupação do solo em uma bacia hidrográfica que possui problemas de inundações 
em São Carlos/SP, houve um aumento na vazão do escoamento das águas pluviais a jusante de 50 a $70 \%$.

Em estudo semelhante de Zanandrea, Silveira e Michel (2018), porém na ocupação de uma bacia hidrográfica também bastante adensada no município de Viamão/RS, em que se adota uma taxa de permeabilidade de apenas 10\%, foi concluído que houve um aumento na vazão do escoamento das águas pluviais a jusante de $16 \%$.

\subsection{Suscetibilidade a inundações}

Ao analisar a suscetibilidade a inundações nas zonas que permitem as maiores taxas de ocupação, buscou-se avaliar se a ocupação urbana, potencializada por esse índice urbanístico, está sendo promovida de maneira adequada em relação a gestão de riscos de desastres.

No município de Rio do Sul, como visto na tabela 3, as duas zonas com as maiores taxas de ocupação são as zonas ZR2 e ZR3, com índices superiores a 60\%. Ao sobrepor essas zonas ao mapa de inundação com a cota do nível do rio em 10,50 m (valor próximo a cota das inundações de 2013, 2015 e 2017), foi notado que 13\% da zona ZR2 e 92\% da ZR3 estão suscetíveis a inundação.

Para o município de Itajaí, as zonas ZU2, ZU3, ZU4 e ZEU, como visto na tabela 1, possuem taxas de ocupação de $80 \%$ e áreas relativas superiores a $1 \%$. Ao sobrepor as zonas descritas com o mapa de inundação de 2011, os resultados obtidos foram:

- Zona ZU2 tem 32\% de sua área suscetível a inundação;

- Zona ZU3 teve 60\% de sua área suscetível a inundação;

- Zona ZU4 teve $65 \%$ de sua área suscetível a inundação;

- Zona ZEU teve 34\% de sua área suscetível a inundação.

\subsection{Outras medidas intra-lote}

Para as medidas intra-lote, foi observado que as legislações municipais de Rio do Sul e Blumenau incentivam à captação de águas das chuvas. Em Rio do Sul, a abordagem é em forma de diretriz, contida no Art. 14 do seu plano diretor, em que visa a implantação de "programas para a manutenção e reserva de águas pluviais" (RIO DO SUL, 2006). Já Blumenau foi além, ao possuir a Lei complementar № 691, de 29 de setembro de 2008 (BLUMENAU, 2008), que instituiu o programa de conservação e uso racional de água no município. Por meio dessa lei, foi estabelecido às novas edificações de uso não-residencial, com área construída superior a 750,00m2, sistema de captação de águas das chuvas, bem como a obrigatoriedade desse sistema para imóveis utilizados na atividade de lavação de veículos (BLUMENAU, 2008).

Apesar das medidas favoráveis à captação das águas das chuvas, foi observado que a abordagem em relação ao assunto, para Blumenau e Rio do Sul, visa somente ao combate à escassez hídrica. Contudo, Rezende e Tecedor (2017) afirmam que a captação de águas das chuvas pode também ser uma medida não estrutural no sistema de drenagem urbana, que regula a carga de águas pluviais destinadas aos componentes do sistema de drenagem, apresentando-se como boa 
alternativa no combate das inundações urbanas. Além disso, há que ser destacado que o estado de Santa Catarina possui muitos episódios de chuvas e pequenas estiagens (MONTEIRO, 2001), e que especificamente a bacia hidrográfica do rio Itajaí, apresenta frequentes registros de inundações e enxurradas (VIEIRA, SCHMIDT, MOURA, 2019), o que torna a necessidade da captação de águas das chuvas ter o foco mais urgente para controle de vazão do que para o combate à escassez hídrica.

Outra medida relacionada está contida na Lei complementar $\mathrm{N}^{\circ} 1.174$, de 7 de fevereiro de 2018 (BLUMENAU, 2018) que regula a utilização de "telhado verde" nas edificações de Blumenau. Conforme o Art. 63-E da referida lei, quando o "telhado verde" for utilizado como área permeável, deverá ser implantado um reservatório de retardo, para acumular as águas da chuva e posteriormente descarregar na rede pública. O benefício do retardo de águas pluviais em "telhados verdes" tem sido consolidado em estudos de quantificação, como o de Santos et al. (2013), ao constatarem que o "telhado verde" reduz o escoamento superficial de $15 \%$ a $30 \%$, enquanto Tassi et al. (2014) verificaram uma redução de $62 \%$.

\section{Conclusão}

Em vista o risco de inundações estar envolvido diretamente com os índices urbanísticos, a gestão pública deve tomar as medidas necessárias para não promover a exposição da sua população ao incentivar a ocupação em áreas suscetíveis. Além disso, definições equivocadas quanto aos índices urbanísticos podem potencializar a probabilidade de ocorrência de inundações, ao permitir a ocupação e impermeabilização do solo além de sua capacidade de infiltração.

Com base na análise comparativa entre os índices urbanísticos dos três municípios estudados, permitiu-se observar uma grande disparidade entre seus dados. Em relação a taxa de ocupação versus as áreas suscetíveis a inundações, foi notado que nos municípios analisados, todas as zonas que possuem incentivos a uma maior ocupação do solo estão suscetíveis a inundações, algumas em mais de $60 \%$ da área, o que torna o valor da taxa de ocupação para estas zonas incoerente, pois aumentam as chances de riscos de desastres por inundações.

No que diz respeito a taxa de permeabilidade, foi observado que embora os três municípios sofram em comum as consequências das inundações, suas abordagens são bastante diferentes sobre a taxa de permeabilidade em seu território. Em Itajaí, por exemplo, permite-se que seu território urbano seja impermeabilizado em quase $90 \%$, ou seja, no caso de a cidade ser totalmente ocupada ao longo do tempo, terá apenas $10 \%$ de área de solo descoberto para infiltração da água, o que é um valor bastante alarmante. O município de Blumenau tem um valor um pouco mais brando, porém igualmente preocupante, pois as águas pluviais que não forem infiltradas no seu próprio solo chegarão mais rapidamente nos diversos municípios a jusante, como Itajaí, podendo causar sérios impactos.

Já o município de Rio do Sul apresentou os índices mais adequados, principalmente na taxa de permeabilidade da área urbana, proporcionando mais da metade de sua área livre.

Em relação às medidas intra-lote, no que tange a captação de água das chuvas, abordadas em Blumenau e Rio do Sul, o foco das legislações municipais tem 
sido exclusivamente para fins de escassez hídrica. Esse foco entra em contraste com as condições vivenciadas pelos municípios, pois as estiagens não fazem parte do cotidiano de desastres naturais que o assolam. Porém, se o foco dessa medida fosse para o retardamento das águas pluviais aos sistemas de drenagem urbana, a fim de reduzir os riscos de desastres por inundações, a medida poderia ter mais disseminação.

Em relação a utilização de "telhado verde", apenas a legislação municipal de Blumenau (BLUMENAU, 2018) abordou sobre o assunto. Ressalta-se a lei existente regulando a utilização dessa medida, bem como seu foco, estando aliado as condições de inundações vivenciadas pelo munícipio. Quanto ao município de Itajaí, além de possuir as zonas com maiores taxas de ocupação e menor permeabilidade entre os três municípios pesquisados, não foi constatado nenhuma medida intralote de captação de águas pluviais, "telhado verde" ou outra medida para retardar o escoamento das águas da chuva.

Portanto, conclui-se que os índices urbanísticos (taxa de ocupação e permeabilidade) e alguns instrumentos jurídicos dos municípios estudados não têm incentivado a sustentabilidade urbana, pois potencializam a impermeabilização do solo e a geração de um maior escoamento superficial a jusante dos mesmos, exigindo assim medidas estruturais onerosas para reduzir o risco de inundações.

\section{REFERÊNCIAS}

ALMEIDA, L. Q.; CARVALHO, P. F. Riscos naturais e sítio urbano - inundações na bacia hidrográfica do rio Maranguapinho, região metropolitana de Fortaleza, Brasil. Revista Brasileira de Geomorfogia, v. 11, n. 2, p. 35-49, 2010.

ALMEIDA, L. Q.; PASCOALINO, A. Gestão de risco, desenvolvimento e (meio) ambiente: um estudo de caso sobre os desastres naturais de Santa Catarina. In: Centro de estudos e pesquisas em engenharia e defesa civil. UFSC. Disponível em: <http://www.ceped.ufsc.br/wpcontent/uploads/2014/07/gestao_de_risco_desenvolv imento_e_meio_ambiente_no_brasil.pdf >. Acesso em: 22 jun. 2019.

ANELLI, R. L. Uma nova cidade para as águas urbanas. Estudos Avançados, v. 29, n. 84, p. 69-84, 2015.

AVILA, M. R. R.; MATTEDI, M. A. Desastre e território: a produção da vulnerabilidade a desastres na cidade de Blumenau/SC. Revista Brasileira de Gestão Urbana, v. 9, n. 2, p. 187-202, 2017.

BAO, R.; GIUDICE, D. S. Análise da distribuição pluviométrica na cidade de Salvador e seus impactos ambientais: o caso dos deslizamentos em São Caetano no período de 2007 a 2012. Revista Geografar, v. 9, n. 1, p. 180-199, 2014.

BARRIOS, M. M.; CABRERA, J. A.; VEGA-ESTARITA, L. El cambio de paradigma em la cobertura informática de la gestión de riesgo de desastres. Chasqui. Revista latinoamericana comunicación, n. 136, p. 129-144, 2018. 
BEZERRA, M. L. F. D. Taxa de (im)permeabilidade urbana intra-lote: um olhar sob a legislação. Revista Campo do Saber, v. 1, n. 2, p. 26-43, 2015.

BLUMENAU. Lei complementar $n^{\circ} 1174$, de 07 de fevereiro de 2018. Acrescenta seção XXI com artigos 63-A, 63-B, 63-C, 63-D e 63-E ao capítulo VI da Lei complementar $n^{\circ} 1.030$, de 18 de dezembro de 2015, para regular a utilização de "Telhado Verde" nas edificações. Prefeitura Municipal de Blumenau, Estado de Santa Catarina, Brasil.

BLUMENAU. Lei complementar $n^{\circ} 1181$, de 02 de abril de 2018. Dispõe sobre o Plano Diretor do município de Blumenau. Prefeitura Municipal de Blumenau, Estado de Santa Catarina, Brasil.

BLUMENAU. Lei complementar $\mathrm{n}^{\circ}$ 691, de 02 de setembro de 2008. Institui o "Programa de conservação e uso racional de água" no município de Blumenau. Prefeitura Municipal de Blumenau, Estado de Santa Catarina, Brasil.

BLUMENAU. Lei complementar $n^{\circ} 751$, de 23 de março de 2010. Dispõe sobre o código de zoneamento, uso e ocupação do solo no município de Blumenau e dá outras providências. Prefeitura Municipal de Blumenau, Estado de Santa Catarina, Brasil.

BRASIL, Constituição da República Federativa do Brasil de 1988. Disponível em: < http://www.planalto.gov.br/ccivil_03/Constituicao/ConstituicaoCompilado.htm>.

BRASIL, Lei $n^{\circ} 10.257$, de 10 de julho de 2001. Regulamenta os arts. 182 e 183 da Constituição Federal, estabelece diretrizes gerais da política urbana e dá outras providências

BRASIL, Lei no 9.785, de 29 de janeiro de 1999. Altera o Decreto-Lei no 3.365, de 21 de junho de 1941 (desapropriação por utilidade pública) e as Leis nos 6.015, de 31 de dezembro de 1973 (registros públicos) e 6.766, de 19 de dezembro de 1979 (parcelamento do solo urbano). Disponível em: <http://www.planalto.gov.br/ccivil_03/Leis/L9785.htm>. Acesso em: 4 de jul. de 2019.

BRASIL, Lei $n^{\circ}$ 12.608, de 10 de abril de 2012. Institui a Política Nacional de Proteção e Defesa Civil - PNPDEC; dispõe sobre o Sistema Nacional de Proteção e Defesa Civil - SINPDEC e o Conselho Nacional de Proteção e Defesa Civil - CONPDEC; autoriza a criação de sistema de informações e monitoramento de desastres; altera as Leis $\mathrm{n}^{\circ} \mathrm{S}$ 12.340, de $1^{\circ}$ de dezembro de 2010, 10.257, de 10 de julho de 2001, 6.766, de 19 de dezembro de 1979, 8.239, de 4 de outubro de 1991, e 9.394, de 20 de dezembro de 1996; e dá outras providências. Disponível em: <http://www.planalto.gov.br/ccivil_03/_Ato2011-2014/2012/Lei/L12608.htm>.

CANHOLI, A. P. Drenagem urbana e controle de enchentes. 2 ed. São Paulo: Oficinas de Textos, 2015. 
CENTRO UNIVERSITÁRIO DE ESTUDOS E PESQUISAS SOBRE DESASTRES (CEPED). Atlas brasileiro de desastres naturais 1991-2012. 2 ed. Florianópolis: UFSC, 2013.

CODIFICAÇÃO BRASILEIRA DE DESASTRES (COBRADE). Classificação e codificação brasileira de desastres. Disponível em: <https://www.bombeiros.go.gov.br/wpcontent/uploads/2012/06/1.-Codificação-e-Classificação-Brasileira-de-Desastres-

COBRADE2.pdf>. Acesso em: 03 jul. 2019.

COMITÊ DO ITAJAÍ. Plano de recursos hídricos da Bacia do Itajaí: para que a água continue a trazer benefícios para todos: caderno síntese. Blumenau: Fundação Agência de Água do Vale do Itajaí, 2010.

COUTINHO, M. P.; LONDE, L. R.; SANTOS, L. B. L.; LEAL, P. J. V. L. Instrumentos de planejamento e preparo dos municípios brasileiros à Política de Proteção e Defesa Civil. Revista Brasileira de Gestão Urbana, v. 7, n. 3, p. 383-396, 2015.

CRUZ, M. A. S.; TUCCI, C. E. M. Avaliação dos cenários de planejamento na drenagem urbana. Revista Brasileira de Recursos Hídricos, v. 13, n. 3, p. 59-71, 2008.

CUNY, F. Disasters and Development. New York: Oxford University Press, 1983.

DECINA, T. G. T.; BRANDÃO, J. L. B. Análise de desempenho de medidas estruturais e não estruturais de controle de inundações em uma bacia urbana. Engenharia Sanitária e Ambiental, v. 21, n. 1, 2016.

DENALDI, R.; BRAJATO, D.; SOUZA, C. V. C.; FROTA, H. B. F. A aplicação do parcelamento, edificação ou utilização compulsórios (PEUC). Urbe. Revista Brasileira de Gestão Urbana, v. 9, n. 2, p. 172-186, 2017.

ESPÍNDOLA, M. A.; NODARI, E. S. Enchentes inesperadas? Vulnerabilidades e políticas públicas em Rio do Sul-SC, Brasil. Esboços: histórias em contextos globais, v. 20, n. 30, p. 9-34, 2013.

FREITAS, C. M.; SILVA, D. R. X.; SENA, A. R. M.; SILVA, E. L.; SALES, L. B. F.; CARVALHO, M. L.; MAZOTO, M. L.; BARCELLOS, C.; COSTA, A. M.; OLIVEIRA, M. L. C.; CORVALÁN, C. Desastres naturais e saúde: uma análise da situação do Brasil. Ciência \& Saúde Coletiva, v. 19, n. 9, p. 3645-3656, 2014.

GUHA-SAPIR, D.; HOYOIS, P.; BELOW, R. Annual Disaster Statistical Review 2014: The Numbers and Trends. Brussels: CRED. p. 22, 2015.

INSTITUTO BRASILEIRO DE GEOGRAFIA E ESTATÍSTICA (IBGE). Censo demográfico 2010. Rio de Janeiro: IBGE, 2010. 
ITAJAÍ. Lei complementar $\mathrm{n}^{\circ}$ 94, de 22 de dezembro de 2006. Institui o Plano Diretor de gestão e desenvolvimento territorial de Itajaí. Prefeitura Municipal de Itajaí, Estado de Santa Catarina, Brasil.

ITAJAÍ. Lei complementar $\mathrm{n}^{\circ} 215$, de 31 de dezembro de 2012. Institui normas para o código de zoneamento, parcelamento e uso do solo no município de Itajaí. Prefeitura Municipal de Itajaí, Estado de Santa Catarina, Brasil.

KAUFFMANN, M. O.; SILVA, L. P. S. Taxa de impermeabilização do solo: Um recurso para a implementação da bacia hidrográfica como unidade de planejamento urbano integrado à gestão dos recursos hídricos. In: ENCONTRO NACIONAL DE PÓSGRADUAÇÃO E PESQUISA EM PLANEJAMENTO URBANO E REGIONAL, 11., 2005, Salvador. Anais do XI Encontro Nacional de pós-graduação e pesquisa em planejamento urbano e regional - ANPUR. Salvador: ANPUR, 2005.

MACHADO, J. L. F.; MARCUZZO, F. F. N. Aquíferos da bacia hidrográfica do Rio Itajaí no estado de Santa Catarina. In: Simpósio Brasileiro de Recursos Hídricos, 21., 2015, Brasília, DF. Anais... Brasília, DF: ABRH, 2015.

MENA, R. Ampliando nuestra comprensión sobre la creación y reducción del riesgo de desastres en latinoamérica y el caribe. Reder, v. 2, n. 2, p. 1-3, 2018.

MINERVINO, A. C.; DUARTE, E. C. Danos materiais causados à Saúde Pública e à sociedade decorrentes de inundações e enxurradas no Brasil, 2010-2014: dados originados dos sistemas de informação global e nacional. Ciência \& Saúde Coletiva, v. 21, n. 3, p. 685-694, 2016.

OLIVER-SMITH, A.; ALCÁNTARA-AYALA, I.; BURTON, I.; LAVELL, A. A construção social do risco de desastres: em busca das causas básicas. In: MARCHEZINI, V.; WISNER, B.; LONDE, L. R.; SAITO, S. M. (Orgs.). Reduction of vulnerability to disasters: from knowledge to action. São Carlos, SP: RiMa Editora, 2017, p. 97-114.

PINTO, G. I. G. Latín-A: El cambio de paradigma: de la atención de desastres a la gestión del riesgo. Boletín Científico Sapiens Research, v. 2, n. 1, p. 13-17, 2012.

PINTO, V. C. Regime jurídico do plano diretor. Disponível em: <https://www2.senado.leg.br/bdsf/bitstream/handle/id/150/54.pdf?sequence=4>.

Acesso em: 10 jul. 2019.

POLETO, C. SUDS (Sustainable Urban Drainage Systems): Uma contextualização histórica. Revista Thema, v. 8, n. 1, p. 1-12, 2011.

POMPÊO, C. A. Drenagem urbana sustentável. Revista Brasileira de Recursos Hídricos, v. 5, p. 15-23, 2000. 
RIO DO SUL. Lei complementar $n^{\circ} 163$, de 12 de dezembro de 2006. Dispõe sobre o Plano Diretor do município de Rio do Sul. Prefeitura Municipal de Rio do Sul, Estado de Santa Catarina, Brasil.

RIO DO SUL. Lei complementar $n^{\circ} 258$, de 19 de dezembro de 2012. Dispõe sobre o Plano Diretor do município de Rio do Sul. Prefeitura Municipal de Rio do Sul, Estado de Santa Catarina, Brasil.

RIO DO SUL. Lei complementar $\mathrm{n}^{\circ} 300$, de 24 de março de 2015. Altera, acrescenta e revoga dispositivos da lei complementar $n^{\circ} 163$, de 12 de dezembro de 2006, que dispõe sobre o Plano Diretor do município de Rio do Sul. Prefeitura Municipal de Rio do Sul, Estado de Santa Catarina, Brasil.

SIEBERT, C. (Des)controle urbano no vale do Itajaí. In; B. FRANK, B; L. SEVEGNANI, L. (Orgs.). Desastre de 2008 no Vale do Itajaí: água, gente e política (p. 38-51). Blumenau, SC: Agência de Água do Vale do Itajaí, 2009, p. 38-51.

SILVA, E. L.; GOMES, R. A. T.; GUIMARÃES, R. F. Emprego de modelo de susceptibilidade a escorregamentos rasos para gestão de riscos de desastres no município de Vitória-ES. Sociedade \& Natureza, v. 25, n. 1, p. 119-131, 2013.

SILVEIRA, C. A.; DIAS, P.; SCHUCH, F. S. A problemática das inundações em áreas urbanas sob a ótica da permeabilidade do solo. In: CONGRESSO BRASILEIRO DE CADASTRO TÉCNICO MULTIFINALITÁRIO, 11\%., 2014, Florianópolis. Anais do Congresso Brasileiro de Cadastro Técnico Multifinalitário. Florianópolis: UFSC, 2014.

TUCCI, C. E. M. Drenagem urbana. Ciência e Cultura, v. 55, n. 4, p. 36-37, 2003.

UNISDR. Sendai framework for disaster risck reduction 2015-2030. In: United Nations. UN Office for Desaster Risk Reduction. Disponível em: <https://www.unisdr.org/files/43291_sendaiframeworkfordrren.pdf>. Acesso em: 15 jun. 2019.

VALDIVIESO, P. Reducción de riesgos de desastres y desarrollo sustentable en la escala municipal: relaciones entre factores institucionales, decisiones y resultados. Revista Debates, v. 12, n. 2, p. 121-167, 2018.

ZANANDREA, F.; SILVEIRA, A. L. L.; MICHEL, G. P. Avaliação da eficiência hidrológica de taxas de ocupação estabelecidas por políticas urbanas. In: ENCONTRO NACIONAL DE ÁGUAS URBANAS, 12., 2018, Maceió. Anais do XII Encontro Nacional de Águas Urbanas. Maceió: ABRH, 2018.

Rafaela Vieira. Doutorado. Programa de Pós-Graduação em Engenharia Ambiental FURB - Universidade Regional de Blumenau. Professora, pesquisadora e extensionista.rafaela@furb.br 
Leandro José Isensee. Especialista. Programa de Pós-Graduação em Engenharia Ambiental FURB - Universidade Regional de Blumenau. Estudante. leandroisensee@gmail.com

Gilson de Oliveira Claudino. Graduado. Programa de Pós-Graduação em Engenharia Ambiental FURB - Universidade Regional de Blumenau. Estudante. gilson.claudinoo@gmail.com

Como citar: VIEIRA, Rafaela; ISENSEE, Leandro José; CLAUDINO, Gilson de Oliveira. Instrumentos legais como ferramentas para redução de riscos e desastres a inundações. Redes (St. Cruz Sul, Online), Santa Cruz do Sul, v. 25, p. 1953-1972, nov. 2020. ISSN 1982-6745. doi:https://doi.org/10.17058/redes.v25i4.13989.

\section{CONTRIBUIÇÃO DE CADA AUTOR}

a. Fundamentação teórico-conceitual e problematização: Rafaela Vieira, Gilson de Oliveira Claudino, Leandro José Isensee;

b. Pesquisa de dados e análise estatística: Leandro José Isensee, Gilson de Oliveira Claudino;

c. Elaboração de figuras e tabelas: Leandro José Isensee;

d. Elaboração e redação do texto: Gilson de Oliveira Claudino, Leandro José Isensee, Rafaela Vieira;

e. Seleção das referências bibliográficas: Rafaela Vieira, Gilson de Oliveira Claudino, Leandro José Isensee.

Fontes de financiamento: CAPES; UNIEDU/FUMDES (1423/SED/2019); Universidade Regional de Blumenau. 